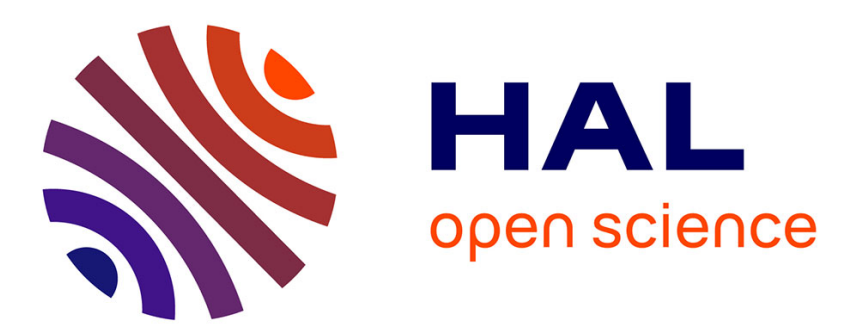

\title{
Is hypertriglyceridemia atherogenic?
}

François Roubille, Ariane Sultan, Fabien Huet, Florence Leclercq, Jean-Christophe Macia, Richard Gervasoni, Delphine Delseny, Mariama Akodad, Camille Roubille

\section{- To cite this version:}

François Roubille, Ariane Sultan, Fabien Huet, Florence Leclercq, Jean-Christophe Macia, et al.. Is hypertriglyceridemia atherogenic?. La Presse Médicale, 2018, 47 (9), pp.s 757-763. 10.1016/j.lpm.2018.08.009 . hal-01884020

\section{HAL Id: hal-01884020 \\ https://hal.umontpellier.fr/hal-01884020}

Submitted on 22 Jan 2020

HAL is a multi-disciplinary open access archive for the deposit and dissemination of scientific research documents, whether they are published or not. The documents may come from teaching and research institutions in France or abroad, or from public or private research centers.
L'archive ouverte pluridisciplinaire $\mathbf{H A L}$, est destinée au dépôt et à la diffusion de documents scientifiques de niveau recherche, publiés ou non, émanant des établissements d'enseignement et de recherche français ou étrangers, des laboratoires publics ou privés. 


\section{L'hypertriglycéridémie est-elle athérogène ?}

\section{Is hypertriglyceridemia atherogenic?}

François Roubille ${ }^{1,2}$, Ariane Sultan ${ }^{2,3}$, Fabien Huet ${ }^{1,2}$, Florence Leclercq ${ }^{1,2}$, Jean-Christophe Macia ${ }^{1}$, Richard Gervasoni ${ }^{1}$, Delphine Delseny ${ }^{1}$, Mariama Akodad ${ }^{1,2}$, Camille Roubille ${ }^{2}$

1. Montpellier University Hospital, UFR de Médecine, Université Montpellier 1, Department of Cardiology, 371, avenue du Doyen-Gaston-Giraud,

34295 Montpellier cedex 5, France

2. Université de Montpellier, PhyMedExp, Inserm, CNRS, 34000 Montpellier, France

3. Montpellier University Hospital, Department of Endocrinology-Diabetes-Nutrition,

34295 Montpellier cedex 5, France

Correspondence:

François Roubille, Montpellier University Hospital, UFR de Médecine, Université Montpellier 1, Department of Cardiology, 371, avenue du Doyen-Gaston-Giraud, 34295 Montpellier cedex 5, France.

francois.roubille@gmail.com

\section{Key points}

ASCVD reduction is based on LDL reduction, especially by statins.

Highly elevated TG could be harmful, especially because of the risk of pancreatitis.

Elevation of TG is mainly due to metabolic disorders and diabetes, alcohol intake and overweight. Genetic factors have been clearly identified in the most severe cases.

TG have been generally considered as bystanders for cardiovascular diseases (CVD).

Both biological and basic research provide strong data suggesting that TG-rich lipoproteins could be involved in the pathophysiology of CVD.

Recent epidemiological and genetics studies strongly corroborate the causal role of TG in CVD. This paves the way for new approaches in the management of patients both for primary and secondary prevention.

\section{Points essentiels}

L'hypertriglycéridémie est-elle athérogène ?

La prévention de la maladie athéroscléreuse est fondée sur la réduction du toux de LDL, particulièrement par l'utilisation de statines.

Des taux élevés de triglycérides (TG) peut être dangereuse, en particulier à cause du risque de pancréatite.

L'ougmentation des TG est principalement liée aux anomalies métaboliques et ou diabète, lo consommation d'alcool et le surpoids. Des facteurs génétiques ont été identifiés dans les cas les plus sévères.

Les TG sont généralement considérés comme des témoins des maladies cardiovasculaires. 
Les approches biologiques et la recherche fondamentale apportent des démonstrations suggérant que les lipoprotéines riches en TG pourraient être impliquées dans la physiopathologie des maladies cardiovasculaires.

Des études épidémiologiques et génétiques récentes confortent puissamment le rôle causal des $T G$ dans les maladies cordiovasculaires.

Cela prépare le terrain pour des nouvelles approches thérapeutiques en prévention primaire et secondaire.

\section{Introduction}

Atherosclerosis is usually considered as a complex pathophysiological phenomenon involving dyslipidemia, oxidative stress, inflammation [1], etc. Among lipids, cholesterol has been identified for decades as an actor of atherosclerosis, in spite of recent controversies especially in our country [2]. Low-density lipoprotein (LDL) has been clearly identified as the main component determining cardiovascular disease (CVD) risk, with various types of evidences including notably the observation of patients with familial hypercholesterolemia with high LDL levels and premature atherosclerotic cardiovascular disease (ASCVD), leading to the Nobel Prize award to Brown and Goldstein in 1985 and the development of statins [3]. Above all, many large, randomized, double blind trials particularly with statins demonstrated that LDL reduction lead to reduce both LDL cholesterol and clinical events such as ASCVD and all-cause mortality [4].

For all these reasons, in clinical practice, the physician focuses on cholesterol, and more especially LDL cholesterol, because its role has been well established. Further, international guidelines clearly recommend management of dyslipidemia depending on the only plasmatic LDL cholesterol level.

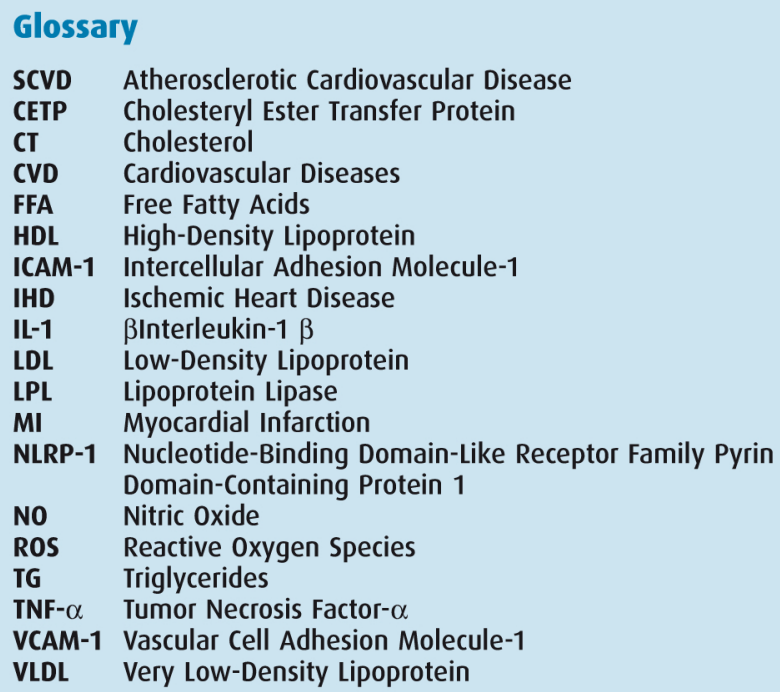

However, not only initial data form the beginning of the lipids story, but also more recent studies suggest that other lipids, including Triglycerides-(TG) rich lipoproteins could be of importance. All together, these data suggest that these lipoproteins are not only bystanders to low high-density lipoproteins (HDL), but could also be actors involved in active pathophysiological pathways of atherosclerosis.

From a clinical point-of-view, the most important is to control and treat a cause of disease. Statins and other treatments lowering LDL have largely demonstrated clinical benefit, corroborating the importance of LDL in the pathophysiology, as a mirror. By contrast, there is no evidence that lowering TG-rich lipoproteins could provide clinical benefit. Importantly, several studies are currently ongoing on this topic.

\section{Definitions}

Figure 1 presents briefly what is measured. Remnant cholesterol can be estimated as: "total cholesterol - LDL cholesterol - HDL cholesterol". When plasmatic level of TG is above $>4 \mathrm{~g} / \mathrm{L}$, LDL cholesterol has to be directly measured.

In the fasting state, remnant cholesterol is mainly present in very low-density lipoprotein (VLDL) and intermediate-density lipoprotein, whereas in the non fasting state, cholesterol is also included in chylomicron remnants.

As TG are the main component of chylomicrons and VLDL particles, they are linked to remnant cholesterol. This is an important point that could contribute to explain the involvement of TG in CVD pathophysiology.

Non-HDL cholesterol is calculated or estimated as total cholesterol minus HDL cholesterol and is equivalent to LDL and remnant cholesterol combined. Importantly, the use of non-HDL cholesterol for cardiovascular disease risk prediction has been emphasized.

\section{Preliminary pathophysiological considerations}

TG can be used for metabolic functions in all the cells, by contrast with $\mathrm{CT}$ (cholesterol). When increased, CT accumulates leading to the deposits in several organs, remaining the well-known cause for ASCVD. CT but not TG has been evidenced in plaques for decades. This is one of the main reasons why TG had not been suspected in ASCVD. Recently, pathophysiological considerations 
have to be modified as first treatment. Independently of the CV risk, the risk of pancreatitis has to be underlined, justifying the dosage of TG per se. Indeed, the cardiologist has to keep in mind the significant risk of pancreatitis in case of severely elevated TG [5] $(>10 \mathrm{mmol} / \mathrm{L} ;>8.80 \mathrm{~g} / \mathrm{L})$. This is the reason why the guidelines advise to reduce levels with the aim of reducing the risk of pancreatitis [5], in spite of the lack of randomized trial in the field.

\section{TG : VLDL+intermediate-density+/-chylomicrons}

\section{FIGURE 1}

Definitions useful for the practitioner. CT: cholesterol; HDL: highdensity lipoprotein; LDL: low-density lipoprotein; TG: triglycerides; VLDL: very low-density lipoprotein.

have moved to at least consider TG as a marker of high levels of cholesterol in TG-rich lipoproteins. The question regarding its involvement as simple markers or actors remains.

\section{High TG and the risk of pancreatitis}

Hypertriglyceridemia has many multifactorial causes summarized in the figure 2 [5]. Alcohol consumption, high fat intake and hyperglycemia have been identified as possibly reversible causes of elevated TG. As a consequence, lifestyle conditions

\begin{tabular}{|l|}
\hline Genetic predisposition \\
\hline Obesity \\
\hline Type 2 diabetes \\
\hline Alcohol consumption \\
\hline Diet high in simple carbohydrates \\
\hline Renal disease \\
\hline Hypothyroidism \\
\hline $\begin{array}{l}\text { Pregnancy (physiological triglyceride concentrations double during the } \\
\text { third trimester) }\end{array}$ \\
\hline $\begin{array}{l}\text { Paraproteinaemia and autoimmune disorders such as systemic lupus } \\
\text { erythematosus }\end{array}$ \\
\hline $\begin{array}{l}\text { Multiple medications including: } \\
\text { - Corticosteroids } \\
\text { - Oestrogens, especially those taken orally } \\
\text { - Tamoxifen } \\
\text { - Antihypertensives: adrenergic beta-blocking agents (to a different } \\
\text { degree), thiazides } \\
\text { - Isotretinoin } \\
\text { - Bile acid-binding resins } \\
\text { - Ciclosporin } \\
\text { - Antiretroviral regimens (protease inhibitors) } \\
\text { - Psychotropic medications: phenothiazines, second generation } \\
\text { antipsychotics }\end{array}$ \\
\hline
\end{tabular}

HyperTG is multifactorial. Adapted for the ESC guidelines [5], with permission.

\section{Historical point-of-view}

Figure 3 presents the point-of view of the authors [6] on the common concepts on lipoproteins. Importantly, initially before the 90s, both LDL and TG were considered to have a significant role in the ASCVD, because of the post-prandial observations. Hence, it was considered important to treat in parallel both elevated TG and CT. Thereafter, a great interest has raised on elevated LDL and guidelines largely ignored mild-to-moderately elevated TG, even if some guidelines propose additional tables on non-HDL CT.

This is easily understandable for many reasons:

- the importance of LDL had been largely established;

- and drug tolerance and interaction might become a problem in case of concomitant treatment of both LDL and TG levels by stain and fibrate association.

In addition to positive randomized, double blind trials (that lack until now regarding TG treatment), several publications provide useful information on epidemiology, genetics, and biology. Taking all these data into account, guidelines were updated and recommend the clinician not to neglect the TG. Indeed, from the beginning of the 2010s, new concepts have progressively emerged, underlining the role of TG and the interest to control them to lower the cardiovascular risk [7-10].

\section{Clinical focus on lipoproteins for ASCVD prevention}

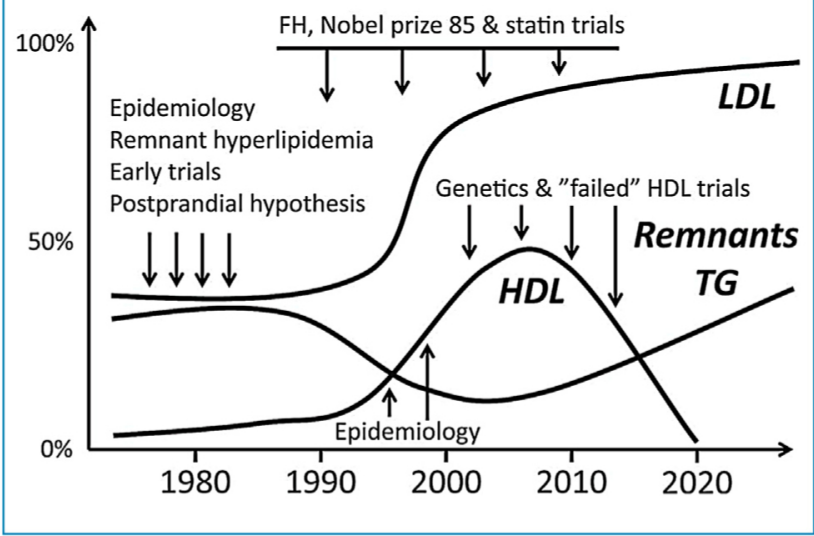

FIGURE 3

Hypertriglyceridemia: an old wine in new bottle. Adapted with permission from [6]. 
Despite this interest, their treatment is not really consensual in clinical practice, as most of trials with fibrates are generally considered as negative regarding clinical outcomes.

Increasing HDL was considered as promising to struggle the CV risk. Unfortunately, in spite of encouraging epidemiological approaches, genetic studies and above all negative large clinical trials with CETP-modulators [11,12] as well as niacin [13] failed to confirm this enthusiasm. There is only one study; the REVEAL study that shows positive results in term of cardiovascular events reduction, using the anacetrapib [14]. It has been suggested that the positive impact could be driven at least partly by the effect on LDL. Unfortunately, the development of the drug was stopped various reasons including commercial ones. Therefore, low HDL has been proposed as rather a bystander or longterm marker of high levels of TG-rich lipoproteins, hence a new interest on TG that could be the real actor. Nevertheless regarding CETP-modulator, promising pharmacological and pharmacogenomics studies $[15,16]$ suggested to better select the patients that could draw benefits and a large clinical pharmacogenomics study: the dal-genE-the first in cardiology-is actually conducted (NCT02525939).

Consistently, as already mentioned long time ago [17], it is actually hypothesized that atherogenesis could take place prominently as a non fasting phenomenon, that is caused by high levels of TG-rich lipoproteins [17].

A large study on 84,177 individuals (see figure 4) described the distribution of non fasting plasma TG and showed that $27 \%$ of adults have mild-to-moderately elevated TG (1.76-8.80 g/L), whereas only $0.1 \%$ of adults have severely elevated TG (>8.80 g/L) [6].

The first generally admitted modifiable causes of elevated TG are diabetes, alcohol consumption and overweight. Recently, genetic factors have been confirmed to participate to mild-tomoderately elevated TG. Further, these genetic factors are the main cause of severely elevated TG (mutations in $L P L, A P O C 2$, APOA5, LMF1, GPIHBP1, and GPD1 genes)[10], paving the way to target therapeutic approaches in these rare but severe patients.

Similarly, $21 \%$ of adults have elevated remnant cholesterol $>1 \mathrm{mmol} / \mathrm{L}(0.4 \mathrm{~g} / \mathrm{L})$.

High levels of TG have been shown to be independently correlated with more elevated risk of ASCVD [18] and even all-cause mortality [19]. Indeed, in the general population (low risk of ASCVD), non fasting TG $>4.40 \mathrm{~g} / \mathrm{L}$ versus $<0.88 \mathrm{~g} / \mathrm{L}$ were associated with 17- and 5-fold risk of $\mathrm{MI}$ in women and men and for all-cause mortality 4- and 2-fold in women and men (figure 5).

\section{Pathophysiology}

TG could be involved at various levels in the pathophysiology of ASCVD, as shown in figure 6.

TG enter easily into the arterial intima, in the heart of the atherosclerotic plaque. It should be noticed that isolated

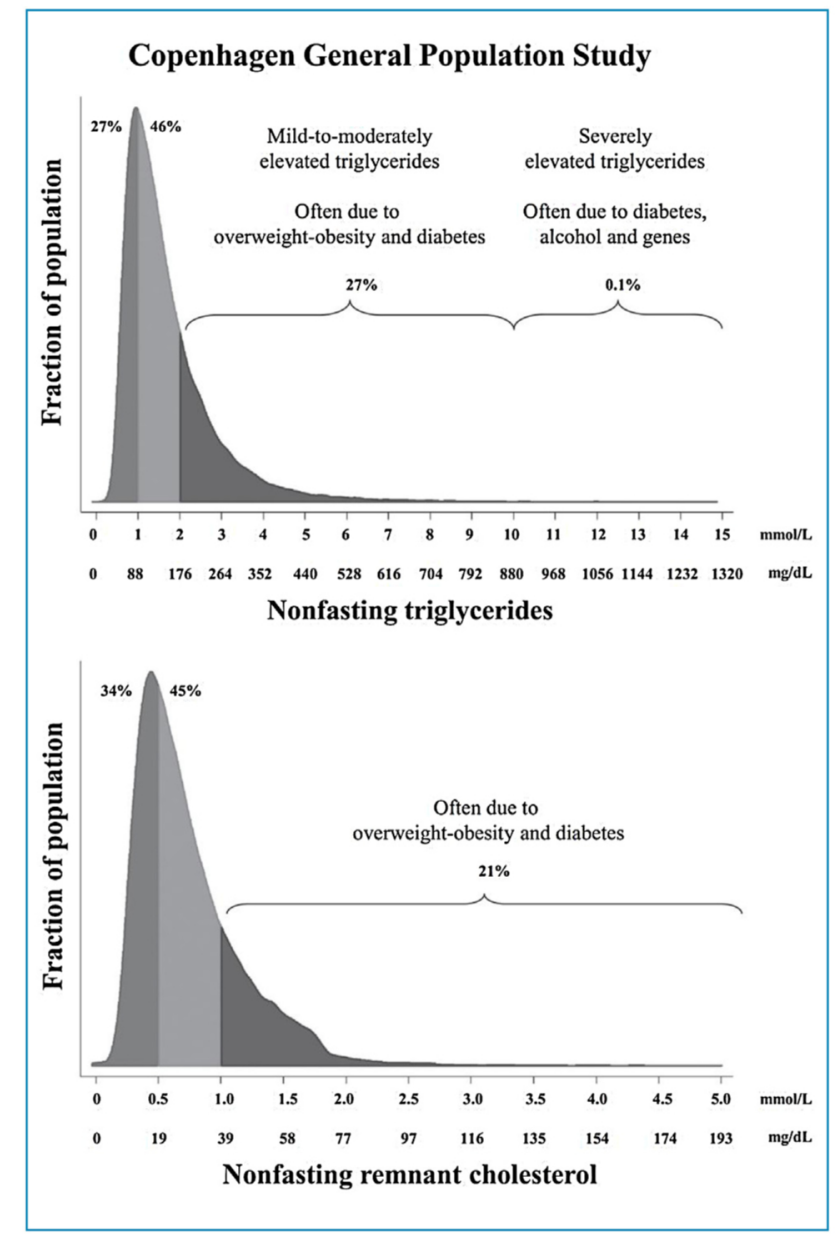

FIgURE 4

Distribution of TG levels in a general population of $\mathbf{8 4 , 1 7 7}$ individuals. Adapted with permission from [6].

elevated plasmatic TG levels do not induce ASCVD. Indeed, patients with chylomicronemia syndrome (leading to severe hyper TG) caused by lipoprotein lipase deficiency, do not present ASCVD. TG could then trigger various pathways. TG are hydrolyzed mainly by the lipoprotein lipase (LPL) and CETPs. Its lipolytic contain various molecules including large amounts of oxidized free fatty acids (ox-FFA) responsible for (1) an increase in production of reactive oxygen species (ROS), (2) a decrease in nitric oxide (NO), (3) an increase in various adherence molecules (ICAM-1, VCAM-1) and other proinflammatory ones (such as NLRP-1). This is the link with other proinflammatory actors (including interleukins TNF- $\alpha$, IL-1 $1 \beta$ ).

\section{New genetics data}

Various genetics approaches provide strong evidence supporting the causal role of TG in ASCVD [20]. Genetics approaches and 


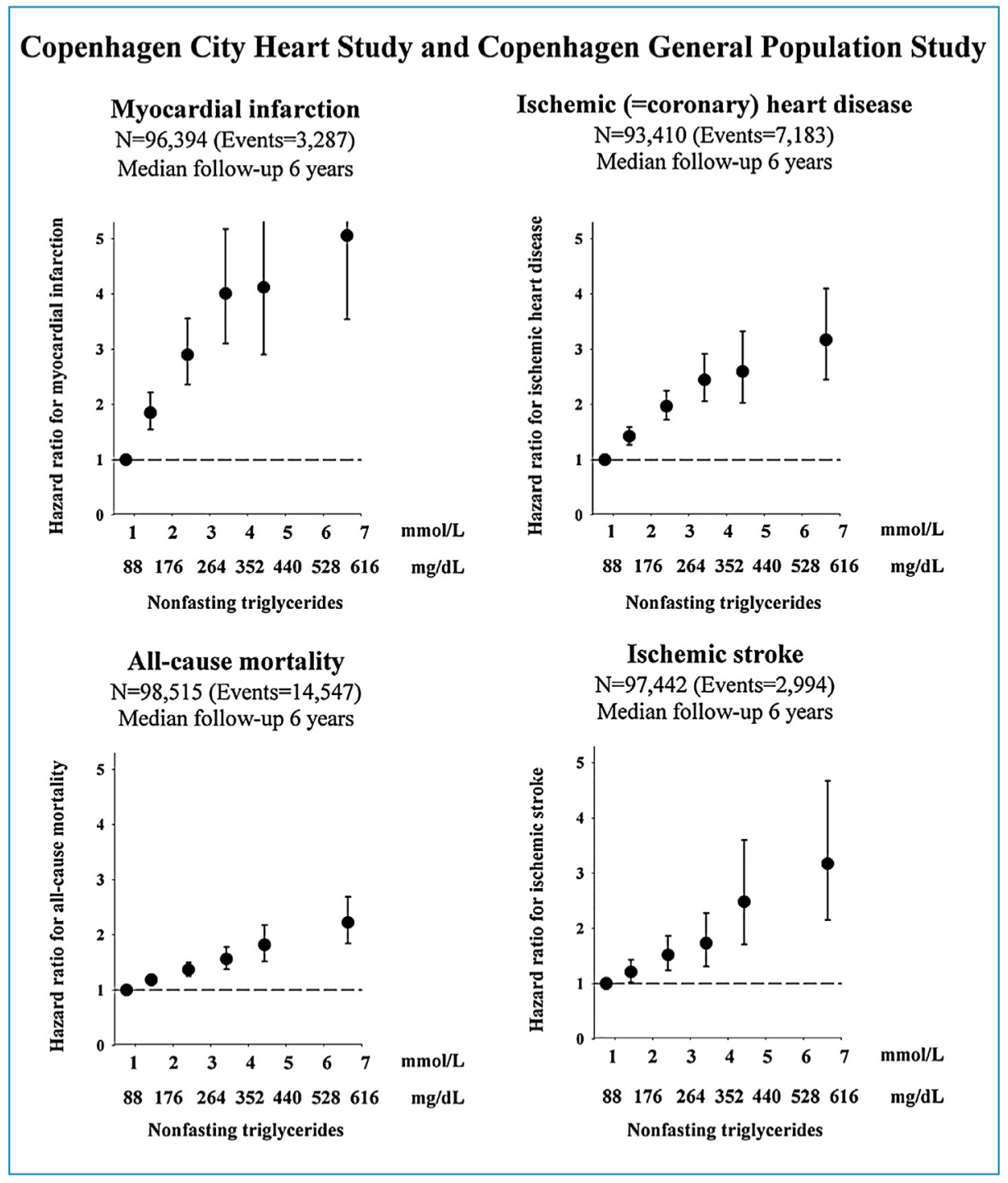

FIGURE 5

Correlations between TG and ASCVD. Adapted from [26] with permission. ASCVD: atherosclerotic cardiovascular disease.

evidences are extensively presented elsewhere [21]. Indeed, large-scale meta-analyses of cohorts and population-based sequencing studies have investigated if some variants in genes could be determinants of plasma TG levels and associated with ASCVD. Some candidates are clearly identified, including: lipoprotein lipase and proteins that interact with it, such as apolipoprotein (apo) A-V, apo C-III and angiopoietin-like proteins 3 and 4. For instance, loss-of-function mutations in APOC3 were associated with low levels of triglycerides and with reduced risk of ischemic cardiovascular disease [22]. More importantly, strong associations with clinical outcomes were established, corroborating the causal link. As a bias, a second lipid disturbance, especially decreased HDL cholesterol was often associated, suggesting a synergic action.

\section{Clinical trials}

Until now, there are no strong data from clinical trials supporting the interest to treat TG for controlling the CVD. The main reason is that no trial evaluated the strategy of reducing TG-rich lipoproteins on ASCVD and all-cause mortality, in patients with elevated TG, except one [23]. Above all, the efficacy of statins in various trials overshadowed the potential interest of strategies targeting TG. Trials with fibrates could provide promising information when subgroups are considered. Nevertheless, they are only old 


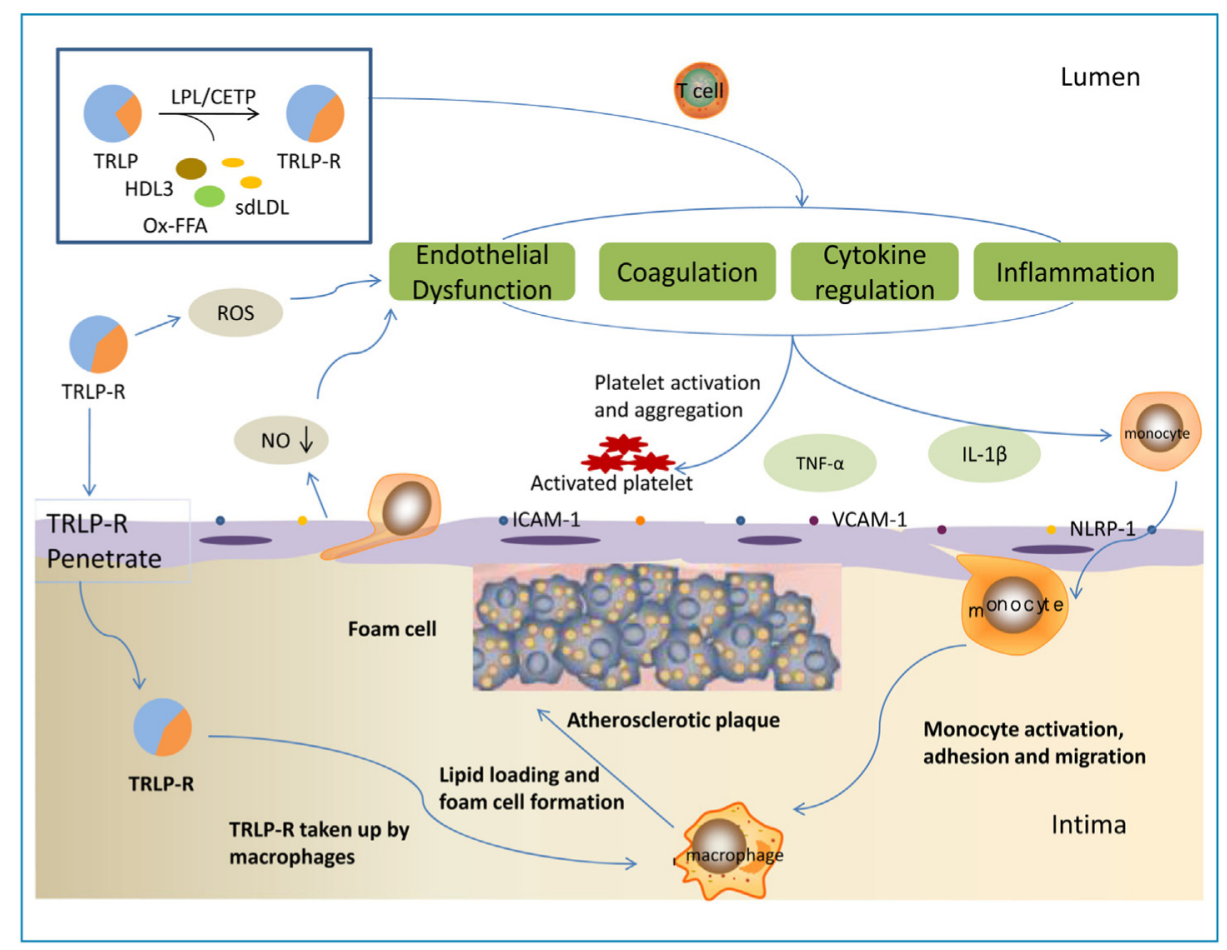

FIGURE 6

Involvement of IG in pathophysiology of atherosclerosis, adapted from [27], open access.

\begin{tabular}{|c|c|c|c|c|c|}
\hline & NCT & & Number of patients & Endpoint & Date \\
\hline Reduce-it & 01492361 & TG lowering n-3 fatty acid: AMR101 & 8000 & MACES Y4-6 & 2018: end of recruitment \\
\hline Strength & 02104817 & Epanova: omega-3 carboxylic acids & 13,000 & MACE & 2019: end of recruitment \\
\hline Prominent & 03071692 & $\begin{array}{c}\text { PPAR- } \alpha \\
\text { Pemafibrate }\end{array}$ & 10,000 & MACE, Y4 & 2022 \\
\hline
\end{tabular}

Clinicaltrials.org, Jan 2017: Phase III, primary endpoint: MACES

studies and management of patients totally changed, urging to tailor new studies in the contemporaneous context.

All the new data briefly presented there taken into consideration, new approaches are currently evaluating the TG hypothesis. For instance, targeting ApoC-III to reduce ASCVD could be obtained through different approaches [24]. Among these, some small clinical trials have shown that innovative options could offer TG reduction in patients. For instance, through selective antisense inhibition of APOC3 synthesis [25], lowering TG levels, among patients with a broad range of baseline levels has been shown possible.

Importantly, many trials are currently investigating the interest of this strategy as presented briefly in toble I. These studies are large PROBE-designed studies and should help to answer the question in the following years.

\section{Conclusions}

TG are of importance for the management of patients. The cardiologist has to keep in mind that LDL alone cannot be the Holy Grail for ASCVD management (both in primary and secondary prevention). New data from biology and basic research but also from epidemiology, genetics and preliminary clinical trials are consistent to support the hypothesis that TGrich lipoproteins could be causal factors for ASCVD. Here, we briefly presented these data and presently growing interest leading to large trials in the field. However, we should keep 


\section{References}

[1] Ross R. Atherosclerosis an inflammatory disease. N Engl J Med 1999;340:115-26.

[2] Bezin J, Francis F, Nguyen NV, Robinson P, Blin $P$, Fourrier-Reglat $A$, et al. Impact of a public media event on the use of statins in the French population. Arch Cardiovasc Dis 2017:110:91-8.

[3] Endo A. The discovery and development of HMG-COA reductase inhibitors. J Lipid Res 1992;33:1569-82.

[4] Baigent C, Blackwell L, Emberson J, Holland LE, Reith C, et al. Cholesterol treatment Trialists C. Efficacy and safety of more intensive lowering of LDL cholesterol: a metaanalysis of data from 170,000 participants in 26 randomised trials. Lancet 2010;376: 1670-81.

[5] Catapano AL, Graham I, De Backer G, Wiklund $\mathrm{O}$, Chapman MJ, Drexel $\mathrm{H}$, et al. 2016 ESC/EAS guidelines for the management of dyslipidaemias. Eur Heart J 2016;37:2999-3058.

[6] Nordestgaard BG. Triglyceride-rich lipoproteins and atherosclerotic cardiovascular disease: new insights from epidemiology, genetics, and biology. Circ Res 2016;118: $547-63$.

[7] Chapman MJ, Ginsberg HN, Amarenco P, Andreotti F, Boren J, Catapano AL, et al. Triglyceride-rich lipoproteins and high-density lipoprotein cholesterol in patients at high risk of cardiovascular disease: evidence and guidance for management. Eur Heart J 2011;32:1345-61.

[8] European Association for Cardiovascular P, Rehabilitation, Reiner Z, Catapano AL, De Backer G, Graham I, et al. ESC/EAS Guidelines for the management of dyslipidaemias: the Task Force for the management of dyslipidaemias of the European Society of Cardiology (ESC) and the European Atherosclerosis Society (EAS). Eur Heart I 2011;32: 1769-818.
[9] Berglund L, Brunzell JD, Goldberg AC, Goldberg IJ, Sacks F, Murad MH, et al. Evaluation and treatment of hypertriglyceridemia: an Endocrine Society clinical practice guideline. J Clin Endocrinol Metab 2012;97:2969-89.

[10] Hegele RA, Ginsberg HN, Chapman MJ, Nordestgaard BG, Kuivenhoven JA, Averna $M$, et al. The polygenic nature of hypertriglyceridaemia: implications for definition, diagnosis, and management. Lancet Diabetes Endocrinol 2014;2:655-66.

[11] Barter PJ, Caulfield M, Eriksson M, Grundy SM, Kastelein J], Komajda M, et al. Effects of torcetrapib in patients at high risk for coronary events. N Engl J Med 2007;357:2109-22.

[12] Schwartz GG, Olsson AG, Abt M, Ballantyne CM, Barter P), Brumm J, et al. Effects of dalcetrapib in patients with a recent acute coronary syndrome. N Engl J Med 2012;367: 2089-99.

[13] Landray M], Haynes R, Armitage J. Niacin for reduction of cardiovascular risk. N Engl J Med 2014:371:1943-4.

[14] Group HTRC, Bowman L, Hopewell JC, Chen $F$, Wallendszus $K$, Stevens $W$, et al. Effects of anacetrapib in patients with atherosclerotic vascular disease. N Engl | Med 2017:377: $1217-27$.

[15] Tardif JC, Rhainds D, Brodeur M, Feroz Zada Y, Fouodjio R, Provost S, et al. Genotypedependent effects of dalcetrapib on cholesterol efflux and inflammation: concordance with clinical outcomes. Circ Cardiovasc Genet 2016:9:340-8.

[16] Tardif JC, Rheaume E, Lemieux Perreault LP, Gregoire JC, Feroz Zada Y, Asselin G, et al. Pharmacogenomic determinants of the cardiovascular effects of dalcetrapib. Circ Cardiovasc Genet 2015;8:372-82.

[17] Zilversmit DB. Atherogenesis: a postprandial phenomenon. Circulation 1979;60:473-85.

[18] Sarwar N, Danesh J, Eiriksdottir G, Sigurdsson $\mathrm{G}$, Wareham N, Bingham S, et al.
Triglycerides and the risk of coronary heart disease: 10,158 incident cases among 262,525 participants in 29 Western prospective studies. Circulation 2007;115:450-8.

[19] Nordestgaard BG, Benn M, Schnohr P, Tybjaerg-Hansen A. Non fasting triglycerides and risk of myocardial infarction, ischemic heart disease, and death in men and women. JAMA 2007:298:299-308.

[20] Varbo A, Benn M, Tybjaerg-Hansen A, Jorgensen AB, Frikke-Schmidt R, Nordestgaard BG. Remnant cholesterol as a causal risk factor for ischemic heart disease. J Am Coll Cardiol 2013;61:427-36.

[21] Dron JS, Hegele RA. Genetics of triglycerides and the risk of atherosclerosis. Curr Atheroscler Rep 2017;19:31.

[22] Jorgensen $A B$, Frikke-Schmidt $R$, Nordestgaard BG, Tybjaerg-Hansen A. Loss-of-function mutations in APOC3 and risk of ischemic vascular disease. N Engl J Med 2014;371: 32-41.

[23] Carlson LA, Rosenhamer G. Reduction of mortality in the Stockholm Ischaemic Heart Disease Secondary Prevention Study by combined treatment with clofibrate and nicotinic acid. Acta Med Scand 1988;223: 405-18.

[24] Khetarpal SA, Qamar A, Millar JS, Rader D]. Targeting Apoc-III to reduce coronary disease risk. Curr Atheroscler Rep 2016;18:54.

[25] Gaudet D, Alexander V], Baker BF, Brisson D, Tremblay K, Singleton W, et al. Antisense inhibition of apolipoprotein C-III in patients with hypertriglyceridemia. N Engl J Med 2015;373:438-47.

[26] Nordestgaard BG, varbo A. Triglycerides and cardiovascular disease. Lancet 2014;384:62635

[27] Peng J, Luo F, Ruan G, Peng R, Li X. Hypertriglyceridemia and atherosclerosis. Lipids Health Dis 2017;16:233. 